Article

\title{
Mutual Support, Role Breadth Self-Efficacy, and Sustainable Job Performance of Workers in Young Firms
}

\author{
Sarah Cheah ${ }^{1, *}$, Shiyu $\mathrm{li}^{1}$ and Yuen-Ping Ho ${ }^{2}$ \\ 1 Business School, National University of Singapore, Singapore 119245, Singapore; shiyu.li@nus.edu.sg \\ 2 Entrepreneurship Centre, National University of Singapore, Singapore 119245, Singapore; \\ yuenping@nus.edu.sg \\ * Correspondence: sarahcheah@nus.edu.sg; Tel.: +65-65167230
}

Received: 21 May 2019; Accepted: 12 June 2019; Published: 17 June 2019

\begin{abstract}
Coworking space has flourished in the past decade. Unlike traditional shared services organizations, coworking spaces put a much greater emphasis on 'sharing'. Members not only can share the physical office space, but also the virtual social spaces created by the coworking space operators managing the office. As coworking spaces provide a community to foster the culture of sharing, which gives rise to social interactions and thus knowledge and idea exchange, entrepreneurs favor such coworking spaces to achieve a higher level of job performance among their workers. Although it is generally accepted that a worker's job performance varies over time within a job, there have been limited studies on within-person performance sustainability and its comparison with between-person sustainability. We sampled 101 workers of young firms operating in six coworking spaces in Singapore who completed daily surveys twice a day across ten consecutive workdays. By treating participants as the first level and daily observations as the second level, our study develops a dual-path model to explain how daily mutual support influences daily job performance. Our results indicated that daily mutual support is positively related to sustainable job performance after controlling for sleep quality, job requirements and workload stress. Within-person sustainability in mutual support was found to account for part of within-person variance in job performance. We established that mutual support not only predicts job performance, but also varies across workdays. As the collaboration of team members depends on cooperation rather than competition, mutual support is considered essential for team work and thus employees' job performance. Our study also demonstrated the importance of role breadth self-efficacy as a moderator in the link between mutual support and sustainable job performance. Role breadth self-efficacy refers to the extent to which people feel confident that they are able to carry out a broader and more proactive role, beyond traditional prescribed technical requirements. The results revealed an enhancing moderation effect, where increasing the role breath self-efficacy would enhance the effect of the mutual support predictor on sustainable job performance of workers in young firms operating in the coworking space.
\end{abstract}

Keywords: young firms; job performance; mutual support; role breadth self-efficacy; coworking space

\section{Introduction}

Individual job performance, referring to things that people actually do and actions they take that contribute to the organization's goals [1], drives the entire sustainable economy [2]. Without the sustainability of individual job performance, there is no sustainable team performance, organizational performance, economic sector performance, nor gross domestic product (GDP). Due to the importance of individual job performance, considerable studies on the subject have been conducted across various 
fields including service [3,4], education [5], marketing [6], management [7] and psychology [8]. From the extant literature, it is apparent that a worker's job performance depends on a range of factors comprising job type, self-esteem, emotional stability and workload [8,9]. According to Callewaert and Robert [10], the culture of sustainability in job performance is a notion that describes a set of behaviors, degrees of engagement and contributions to sustainable development at individual and organizational levels. By postulating the concept of employee sustainable performance, Jiang, Zhao, and Ni [11] reveal that an individual's sustainable performance is positively influenced by transformational leadership. Based on job demands-resources theory $[12,13]$ that explains how job stress and motivation are affected by job demands and job resources, Bakker and Demerouti [14] used multilevel approach to demonstrate how managers and supervisors can help employees to avoid job stress and enhance well-being and job performance. However, so far, job performance literature has not focused on young firms. Our study aims to address this gap by looking at employees' job performance working in young firms located at coworking spaces.

There are several reasons for young firms to turn to coworking spaces. First, with advances in telecommunication technologies and rise in cross-border trade, knowledge workers are increasingly expected to coordinate their tasks with other workers, suppliers, customers or partners operating from diverse geographical locations in different time zones. Due to the changing nature of work enabled by mobile computing, these knowledge workers are able to work anywhere as long as they are given access to the internet, email and telephone. As the workers become more mobile, the need for a firm to enter into long-term lease of a conventional office with fixed space and furniture for them to utilize during regular work hours decreases. With limited financial resources, young firms will find it more cost-effective to get into short-term leases with coworking space operators that offer tenant firms office space and meeting rooms on-demand.

Second, as young firms expand internationally, their need for office space in their target foreign markets increases. Besides housing local hires, these firms will need office space to host meetings with local partners and prospective customers. As coworking space operators compete to meet the internationalization needs of these young firms, the former have also expanded their overseas network by organic growth, acquisition or collaboration with local layers to provide the latter seamless access to the local community. By having such access, young firms are able to plug into the local market quickly for talent, venture capital, technology, and other essential resources for venture expansion [15].

Finally, unlike traditional shared services organizations, coworking spaces put much greater emphasis on 'sharing'. Members not only can share the physical office space, but also the virtual social spaces created by the coworking space operators managing the office. Coworking spaces are generally designed to engender a community to foster the culture of sharing, which gives rise to social interactions and thus knowledge and idea exchange. Believing that the social climate of coworking spaces can promote a sense of belonging, self-efficacy, work enjoyment and job performance among their workers, young firms tend to favor such spaces. Fueled by the above developments, coworking space has flourished in the past decade and gained increasing interest among academics and policymakers.

Although it is generally accepted that a worker's job performance varies over time within a job, very little is known about how and why it varies in this manner in the literature of young firms. This study aims to investigate how a worker's job performance in a young firm varies within oneself (within-person sustainability), and compare it with that between workers (between-person sustainability). In this research, we sampled 101 workers of young firms operating in six coworking spaces in Singapore who completed daily surveys twice a day across ten consecutive workdays. By treating participants as the first level and daily observations as the second level, our study develops a dual-path model based on self-determination theory and social exchange theory to explain how daily mutual support influences daily job performance. With the further application of the expectancy-value theory, we examine how RBSE can influence the link between daily mutual support and daily job performance. 
Our results indicated that daily mutual support is positively related to daily job performance after controlling for sleep quality, job requirements and workload stress. Within-person sustainability in mutual support was found to account for part of within-person variance in job performance. We established that mutual support not only predicts job performance, but also varies across workdays. As the collaboration of team members depends on cooperation rather than competition, mutual support is considered essential for team work and thus employees' job performance.

Our study also demonstrated the importance of role breadth self-efficacy (RBSE) as a moderator in the link between mutual support and sustainable job performance. RBSE refers to the extent to which people feel confident that they are able to carry out a broader and more proactive role, beyond traditional prescribed technical requirements. The results revealed an enhancing moderation effect, where increasing RBSE would enhance the effect of the mutual support predictor on sustainable job performance of workers in young firms operating in the coworking space.

\section{Background and Hypotheses}

\subsection{Daily Mutual Support and Sustainable Job Performance}

In the research of entrepreneurship, the concept of social interaction refers to the interaction among members of entrepreneurial teams. Based on a study of more than 150 German entrepreneurial teams, Lechler [16] empirically established that social interaction is a significant factor to business success. Social interaction was posited to comprise six dimensions [16]: communication [17], cohesion [18], work norms [19], mutual support, coordination and the balance of member contributions [20]. In particular, mutual support concerns the cooperation rather than competition among team members. It is considered critical for teamwork [21,22]. In its most basic form, mutual support is defined as "a process in which persons voluntarily come together to help each other address common problems or shared concerns" [23] (p. 168). In a work environment where there is mutual support, workers will attempt to complement each other and strive to engage in constructive and beneficial discussion, with the view to reaching consensus on important issues. In a cooperative atmosphere, workers can feel mutual respect when discussing their proposals and contributions for meaningful development.

As a high level of social support buffers the individual against the negative consequences of stressors at work [24], a supportive environment is important for the individual to develop work enjoyment and productivity. Baruch-Feldman et al. highlighted that the supervisor also plays an important role in rendering support to workers by demonstrating that immediate supervisor support was positively correlated to employees' job satisfaction and productivity [25]. Earlier research has confirmed that an increase in productivity can lead directly to an increase in job performance [26].

An alternative explanation for the positive relationship between mutual support and job performance could be the role of the worker's psychological state. Genero et al. found that low spouse or partner mutuality was predictive of significant depressive symptoms which can negatively impact the cognitive and emotional states of a person [27]. Mutual support has been proven to be associated with affective commitment [28,29] and positive psychological outcomes [30]. According to the self-determination theory [31], the fulfillment of three basic psychological needs-need for autonomy, need for competence and need for relatedness-could result in the state of well-being, social development, and positive behaviors of individuals such as high level of job performance [32]. Ilardi et al. illustrated that psychological needs satisfaction is essential for well-being at work [33].

Numerous studies have examined the relationship between mutual support and job performance, most of which focus on the leader-follower mutuality $[29,34]$. The social exchange theory is frequently used and defined as the "voluntary actions of individuals that are motivated by the returns they are expected to bring and typically do in fact bring from others" [35] (p. 91). Based on the theory, Clarke and Mahadi found that mutual respect between leaders and followers is positively associated with followers' job performance [29]. In a young firm that is relatively small in staff strength and flat in its hierarchical structure compared to a mature firm, workers in the former are likely to play more 
multiple roles and interact more closely as a founding team than those in the latter. This means the relationships between superiors and subordinates might be weaker while the mutual support among coworkers stronger in young firms than those in mature firms.

To understand the sustainability of job performance, Jiang, Zhao and Ni's study of 389 project teams analyzed task sustainable performance and relational sustainable performance, which refer to, respectively, the extent to which employees achieve their own sustainable development by meeting their tasks on time, and the extent to which employees contribute to the organizational goal and the sustainability of organizational culture [11]. A recent study by Nguyen found several important determinants for the sustainable performance of small and medium enterprises (SMEs), such as managerial support, environment, motivation, and engagement of all members in the organization [36].

Building on their works [11,36], we hypothesize that workers who receive daily mutual support are likely to achieve sustainable job performance on the same day.

Hypothesis 1 (H1): Daily mutual support will be positively related to sustainable job performance on the same day.

\subsection{The Moderating Role of Role Breadth Self-efficacy (RBSE)}

The concept of self-efficacy was first developed by Bandura [37] as "an individual's conviction (or confidence) about his or her abilities to mobilize the motivation, cognitive resources, and courses of action needed to successfully execute a specific task within a given context" [38] (p. 66). This suggests that workers having the same abilities may perform differently from one another depending on how their self-confidence about their abilities boost or hinder their motivation or efforts. In Anderson, Chen and Carter's health promotion study of US church institutions, self-efficacy was found to contribute to individuals' physical activity levels, although its effect was relatively less significant compared to other social-cognitive variables such as self-regulation [39]. Using a multilevel approach, Yeo and Neal found that task-specific self-efficacy was negatively correlated to task performance at the within-person level. However, the average levels of task-specific self-efficacy were positively correlated to task performance at between-person level [40]. These findings highlight the significance of adopting a multilevel approach in explaining self-efficacy.

Building on the self-efficacy concept, Parker developed a particular type of self-efficacy RBSE, which describes the extent to which people feel confident that they are able to carry out a broader and more proactive role, beyond traditional prescribed technical requirements [41]. Employees with high RBSE are more likely to feel that they can control the situation and be capable of accomplishing more challenging tasks [42]. On the other hand, those with low RBSE tend to be less proactive as they have less confidence in their capabilities [43].

Drawing on the self-determination theory [31] and expectancy-value theory [44], which is a process theory of motivation that defines three components (effort, rewards, valence) relating positively to level of performance, Fuller et al. argued that RBSE reflects the "can do" motivational states [45]. They also found RBSE to be an essential predictor of proactive behavior. Once coworkers decide to behave proactively, they become intrinsically motivated and attempt to meaningfully alter the self to make some contributions to the organization [46]. As Zapata-Phelan et al. demonstrated, intrinsic motivation can lead employees to perform better tasks [47].

Some studies have found that RBSE relates positively to job performance because it influences both the activities that people pursue and how much effort they allocate to these activities. However, others have revealed that high levels of RBSE may impair performance [48]. This might happen when employees are given ambiguous tasks. When employees have a clear overall goal and specific feedback about their work, RBSE was posited to positively predict job performance [49]. Although these mixed findings might be attributed to situational factors such as goal clarity, more studies are required to empirically investigate the relationship between RBSE and job performance. 
Extending the works of Tims et al. which established that day-level self-efficacy has a positive relationship with day-level performance [50], we hypothesize that, at day level, the relationship between mutual support and sustainable job performance would be stronger for employees with high RBSE, compared with those with lower RBSE.

Hypothesis 2 (H2): Daily role breadth self-efficacy (RBSE) will moderate the relationship between daily mutual support and sustainable job performance on the same day.

Analysis at day level would allow us to make cross-sectional comparison across employees, track an individual employee over time and study the sustainability of job performance within coworkers. The conceptual model is shown in Figure 1.

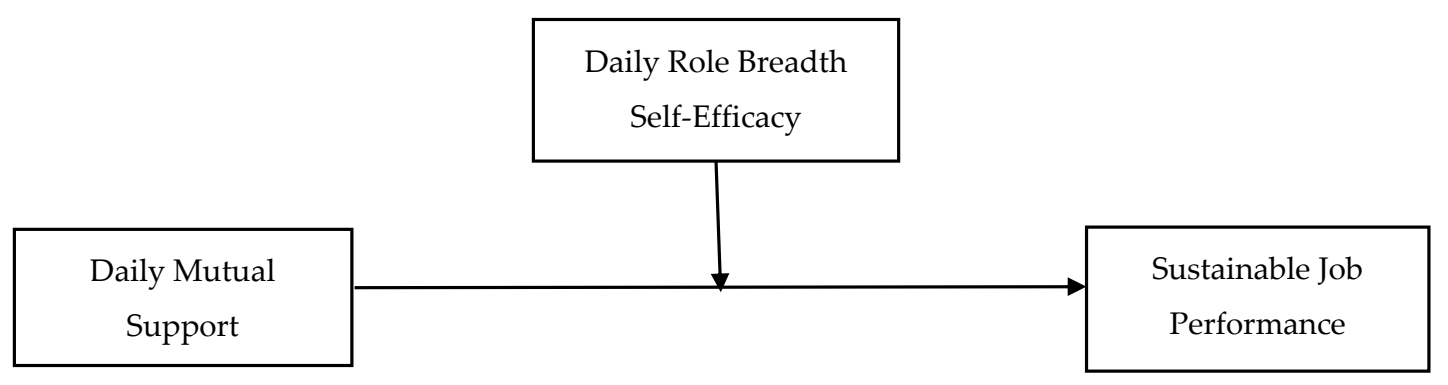

Figure 1. Conceptual model.

\section{Methods}

\subsection{Data Collection and Sample}

The sample comprised employees from young firms operating in coworking spaces in Singapore. Coworking spaces refer to a shared working environment where diverse groups of people who do not necessarily work for the same company or on the same project, work alongside each other and share the office space and resources [51]. According to Davidson et al. [23] (p. 168), mutual support can be provided by persons who "voluntarily come together to help each other address common problems or shared concerns". The persons offering mutual support do not necessarily work for the same company or the same project, as in a coworking space. They may simply participate in mutual support to increase their social network, receive social acceptance or seek solutions [52,53]. Of the seven coworking space operators we contacted, six agreed to help us inform their tenant firms about the study. Their tenants were primarily young firms that rented office space from the operators to house their workers. When recruiting their employees working in the coworking space in Singapore, we emphasized voluntary participation, assuring data confidentiality, and identity anonymity.

\subsubsection{Daily Noon Time Survey, Daily Evening Survey, and One-Time Peer Survey}

Among the 281 members who were working at the six coworking spaces at the time of the study, 204 members agreed to participate. After prospective participants registered online, they were invited to complete a one-time baseline survey, which captured their background information such as gender, age, designation and nationality. In the baseline survey, participants were also requested to nominate one of their coworkers as peers for objective rating of the participants' job performance. These participants were then asked to complete two daily surveys using their mobile phone for ten consecutive workdays. The first daily survey was conducted at noon, before the participants started their afternoon work. The purpose of the noon survey was to assess the level of participants' RBSE and the mutual support they received from their coworkers during the morning. The second daily survey was conducted at the end of workday, when participants were asked to report their job performance. All assessments were time stamped in the online survey system. 
After the participants completed the daily surveys for ten working days, we invited their peers (one peer per participant) to respond to a one-time survey on the participant's job performance. In the individual differences literature, some studies suggest self-reported measures of job performance may be biased due to participants' desire for social acceptance [54] and hence advocated the need for peer ratings of job performance [55]. Other studies, on the other hand, found that self-reported measures were affected by individuals' observations or experiences rather than bias and established convergence between self-measures and peer-based measures [56]. Building on these works, this study captured peer ratings to assess the validity of participants' self-reported responses on the latter's job performance.

To compensate them for their time, the participants were paid S\$100 each upon successful completion of the ten-day diary study, while their nominated peers were given $\$ 10$ each for their one-time survey completion.

\subsubsection{Participant Overview}

To ensure the accuracy of data analysis, we required the participants to complete surveys during the specific time slots. Of the 204 participants, we first excluded those participants whose data had incompatible time stamps with the instructions given to them. Second, the measures of all variables were not collected on holidays or weekends. Data with missing values were also excluded. Third, we excluded those days on which participants were on leave, as we aimed to analyze the relationship between mutual support and job performance at the coworking space, so their physical presence at the space was a requirement for valid response.

This procedure led to a total number of 101 participants, showing a response rate of $49.5 \%$. The 101 participants comprised Singaporeans (83\%), Chinese (7\%), Malaysians (4\%), Filipinos (2\%), Indians $(2 \%)$, and Koreans ( $2 \%) .60$ of the participants were male (59\%) while 41 are female $(41 \%)$. The mean age was $28.77(\mathrm{SD}=6.28)$, ranging from 20 to 54 years old and the average job tenure was 29.24 weeks $(\mathrm{SD}=32.15)$. As young firms are more likely than mature firms to rent desks compared to rooms at the coworking spaces, we found that our sample was generally made up of younger and more male individuals with little work experience.

\subsection{Measures and Variables}

\subsubsection{Independent Variable}

The independent variable 'mutual support' is operationally defined as support provided by the staff of young firms operating at the coworking space. We measured 'mutual support' with the first survey at noon. Four items were adapted from previous social interaction research at the Stevens Institution of Technology [16]. The items including "the coworking team members/tenants support and complement each other as well as they can", "discussions among the coworking team members/tenants are constructive and beneficial", "proposals and suggestions of coworking team members/tenants are respected", "I work within a cooperative ambience", were answered on five-point Likert scales ranging from 1 = strongly disagree to 5 = strongly agree. Cronbach's Alpha for this scale is 0.98 .

\subsubsection{Moderating Variable}

The moderating variable, 'RBSE' is operationally defined as the RBSE of the staff of young firms operating at the coworking space. It was assessed at noon time survey, using a seven-item measurement based on a cross-sectional study by Parker [41]. Coworkers were asked to report at the noon survey how confident they felt on "analyzing a long-term problem to find a solution", "designing new procedures for their work", "contributing to discussion about the company's strategy", "writing a proposal to request for funding in their work", "helping to set targets/goals in their work area", "contacting people outside company (e.g., suppliers, customers) to discuss problems", "presenting 
information to a group of colleagues", on a five-point scale ranging from $1=$ not at all, $2=$ slightly, $3=$ somewhat, $4=$ moderately, and $5=$ extremely. Cronbach's Alpha for this scale is 0.94 .

\subsubsection{Dependent Variable}

The dependent variable 'sustainable job performance' is operationally defined as the daily job performance of the staff of young firms operating at the coworking space. From every individual worker, we captured ten different self-reported job performance ratings in the evening survey during a period of ten consecutive working days. Daily 'sustainable job performance' was measured by a four-item scale from Welbourne, Johnson, and Erez [57]. Individuals responded to items "quantity of work output", "quality of work output", "accuracy of work", and "customer service provided", with a Cronbach's Alpha of 0.81 .

As 101 participants completed daily questionnaires over a period of ten days, we successfully collected a total of 1010 observations for each of the three variables: 'mutual support', 'RBSE', and 'sustainable job performance'.

\subsubsection{Control Variables}

Three variables were controlled when we tested our model. Nebes et al. suggested that poor sleep is associated with decreased concentration, which may lead to poor job performance [58]. Daily sleep quality was measured, in the noon survey, by a single item that "How do you evaluate your sleep quality last night" with a scale from $1=$ very poor to $5=$ very good. In the evening survey, we included 'job requirements' and 'workload stress' as control variables, which may account for differences in creative behaviors.

We controlled for daily 'job requirements' as organizations require different levels of performance in different jobs. Daily 'job requirements' was measured with five items adopted from Yuan and Woodman [59], "my job duties include searching for new technologies and techniques", "introducing new ideas into the organization is part of my job", "I don't have to be innovative to fulfil my job requirements", "my job requires me to try out new approaches to problems", and "suggesting new ideas is part of my job duties". Cronbach's alpha of 'job requirements' is 0.80 .

It is important to control for daily 'workload stress' as excessive or undesirable constraints may interfere with individuals' ability to accomplish their daily tasks. Daily 'workload stress' was measured by five-item scale from Cavanaugh et al. [60]. The items were "today, I worked on many tasks and assignments", "today, I had a lot of work to do", "today, I experienced time pressure", "today, I had a lot of responsibilities", "today, I had to work fast" with Cronbach's alpha of 0.97.

Among the seven study variables, alpha values range from 0.79 to 0.98 . The strength of these reliability estimates indicate a high homogeneity among the scale items.

\subsection{Data Analysis}

For robust data analysis, there is a need to address the issue of potential bias in self-reported survey data. As self-reported questionnaires and performance-based evaluations have inherent limitations, such as poor recall, both intentional and unintentional distortions by participants [54,61,62], we gathered peer-ratings on the participants' job performance as more objective evaluations, which were not the dependent variable, but were used only to assess the validity of participants' responses on their own job performance $[55,56]$. We proceeded to compare the difference between the average of ten measurements provided by each of the participants' and their nominated peers' scores on job performance. One-way analysis of variance (ANOVA) was used to determine whether there were any significant differences between the participants' responses on job performance and their nominated peers' rating on their job performance. Job performance was centered by subtracting its mean value since the average of job performance from participants was 3.67, while that from colleagues, who preferred to rate their coworkers higher, was 4.28. After centralization, one-way ANOVA generated a 
F-statistic of 0.244 , with a $p$-value of 0.622 , showing no significant difference between mean values of job performance from the two groups. Hence, the validity of participants' job performance was confirmed.

Multilevel modelling (MLM) is appropriate for the analysis of longitudinal data, given that ten-wave measurement points (level 1) in our case are nested within 101 individuals (level 2). Ignoring the nested structure of such longitudinal data can result in biased estimates of standard errors and subsequent increase in Type I error, the rejection of true null hypothesis [63]. More importantly, we group-centered the predictors by calculating the difference between a single observation and the mean of ten observations from one individual. As indicated by Wooldridge [64], centering is an effective way to avoid collinearity caused by highly correlated random intercepts and slopes in MLM. Moreover, the group centering approach eliminates all the between-individual variance in the predictors and therefore the estimates represent strictly within-individual relations [64-66]. Using the group mean centered values of predictors in the analysis would therefore mean that we are investigating the relationship between an individual's sustainable job performance over a period of time and their daily mutual support.

The two hypotheses were tested through MLM in R [67]. To examine Hypothesis 1, we used the independent variable 'mutual support' and three control variables to predict 'sustainable job performance'. In Hypothesis 2, 'RBSE' was tested as a moderator in the link between 'mutual support' and 'sustainable job performance'. If Hypothesis 2 is supported, the direction of the moderation effect needs to be discussed as well. The analyses of Hypothesis 1 and Hypothesis 2 were based on a sample of 101 coworkers, and involved a total of 1010 observations each of 'mutual support', 'RBSE', and 'sustainable job performance' over ten days.

\section{Results}

Table 1 presents the mean, standard deviation, between- and within-individual correlations among the variables used in this study. Since high correlations up to 0.77 have been observed between certain variables, variance inflation factor (VIF) values are calculated, which are found to be less than 2 and well below the threshold of ten, addressing any possible concerns about multi-collinearity issues [68].

Table 1. Descriptive statistics and the within and between correlations

\begin{tabular}{|c|c|c|c|c|c|c|c|c|c|c|c|}
\hline & Variables & Mean & SD & 1 & 2 & 3 & 4 & 5 & 6 & CA & VIF \\
\hline 1 & $\begin{array}{c}\text { Sustainable job } \\
\text { performance (evening, } \\
\text { self-rated) }\end{array}$ & 3.67 & 0.71 & - & $0.18^{* *}$ & $0.48^{* *}$ & $0.59 * *$ & $0.28 * *$ & $0.54^{* *}$ & 0.81 & \\
\hline 2 & Sleep quality (noon) & 2.87 & 0.72 & $0.29 * *$ & - & $0.12 * *$ & 0.05 & $0.15^{* *}$ & $0.19 * *$ & & 1.05 \\
\hline 3 & $\begin{array}{l}\text { Job requirements } \\
\text { (evening) }\end{array}$ & 3.46 & 0.71 & $0.61 * *$ & $0.23^{* *}$ & - & $0.46^{* *}$ & $0.24 * *$ & $0.57^{* *}$ & 0.80 & 1.63 \\
\hline 4 & $\begin{array}{l}\text { Workload stress } \\
\text { (evening) }\end{array}$ & 3.50 & 0.97 & $0.71^{* *}$ & 0.11 & $0.60^{* *}$ & - & $0.07^{*}$ & $0.46^{* *}$ & 0.97 & 1.38 \\
\hline 5 & Mutual support (noon) & 3.73 & 0.76 & $0.38^{* *}$ & $0.19^{* *}$ & $0.32 * *$ & 0.07 & - & $0.26^{* *}$ & 0.98 & 1.11 \\
\hline 6 & $\begin{array}{c}\text { Role breadth } \\
\text { self-efficacy (noon) }\end{array}$ & 3.68 & 0.75 & $0.74^{* *}$ & $0.25^{* *}$ & $0.77^{* *}$ & $0.67^{* *}$ & $0.28 * *$ & - & 0.94 & 1.69 \\
\hline 7 & $\begin{array}{l}\text { Performance (peer-rated; } \\
\text { one-time rating) }\end{array}$ & 4.28 & 0.66 & 0.06 & 0.02 & -0.05 & 0.00 & 0.06 & 0.05 & 0.79 & \\
\hline
\end{tabular}

Notes: ${ }^{*} p<0.05 ;{ }^{* *} p<0.01$ (two-tailed), $\mathrm{N}=1010$, VIF: variance inflation factor, CA: Cronbach's Alpha for the within-individual variables, CA was averaged over 10 measurements. The correlation above the diagonal represents within-individual correlations with 1010 observations. The correlation below the diagonal represents between-individual associations by using individuals' average scores during 10 days, $\mathrm{N}=101$.

At the between-individual level, it is important to note that the peer ratings on the participants' job performance did not correlate consistently with the average daily job performance provided by the participants themselves. A plausible explanation of the low cross-sectional validity may be the augmented effects of rating biases such as 'sleep quality' [58]. To reassure the validity of the self-reported 'sustainable job performance', as demonstrated in the previous section, a F-statistic of 
0.244 , with $p$-value of 0.622 generated by one-way ANOVA confirms the validity of 'sustainable job performance' [69]. Furthermore, at the intra-individual level, 'mutual support' and 'RBSE' correlated with 'sustainable job performance' in the expected directions.

\subsection{Main Effect Hypothesis}

Hypothesis 1 suggests that on days when coworkers experience high 'mutual support', they report a higher level of 'sustainable job performance' for that day, compared to days when they experience low 'mutual support'. We used the following two-level model to test this hypothesis, where SQ, JR, WS, MS represent 'sleep quality', 'job requirements', 'workload stress', and 'mutual support', respectively.

Level 1:

$$
Y_{i j}=\beta_{0 j}+\beta_{1 j} S Q_{1 j}+\beta_{2 j} J R_{2 j}+\beta_{3 j} W S_{3 j}+\beta_{4 j} M S_{4 j}+\varepsilon_{i j}
$$

Level 2:

$$
\begin{gathered}
\beta_{0 j}=\gamma_{00}+U_{0 j} \\
\beta_{1 j}=\gamma_{10} \\
\beta_{2 j}=\gamma_{20} \\
\beta_{3 j}=\gamma_{30} \\
\beta_{4 j}=\gamma_{40}
\end{gathered}
$$

In the level 1 model, $Y_{i j}$ represents the 'sustainable job performance' for individual $j$ measured at each day $(1,2, \ldots, 10)$. The intercept $\beta_{0 j}$ can be intercepted as individual $j$ 's mean job performance over time. While in level 2 model, $\beta_{0 j}$ was entered as an outcome and was divided into two parts: $\gamma_{00}$, a fixed effect because it remains constant across all individuals, and $U_{0 j}$, a random effect which varies from individual to individual. $\gamma_{00}$ can be interpreted as the general mean value for 'sustainable job performance' when all control variables and 'mutual support' equal to zero. $\gamma_{10}$ through $\gamma_{40}$ express the relationship between controllers, predictors, and the outcome variable. For instance, holding everything else constant, larger values of $\gamma_{40}$ (positive or negative) indicate a stronger linear relationship between daily 'mutual support' and 'sustainable job performance'.

At level 2, we assumed that the individuals' intercepts were random but other slopes were fixed across individuals. Our implication of the model above is that coworkers' 'sustainable job performance' is impacted by individuals' daily fluctuation (within-person variation), variations among individuals (between-person variation), an overall mean to all individuals $\left(\gamma_{00}\right)$, and the impact of the control variables and predictor as measured by $\gamma_{10}$ to $\gamma_{40}$, which are common to all individuals as well. $\beta_{4 j}$ is of our primary interest, representing the individual slope effect of the time-varying predictor 'mutual support' on the coworkers' 'sustainable job performance'. Essentially, the goal of this model was to examine the extent to which the control variables and the dynamic predictor 'mutual support' could predict the coworkers' 'sustainable job performance'.

In line with our expectations (see Table 2), coworkers with higher 'mutual support' demonstrated a higher level of 'sustainable job performance'. The coefficient of 0.08 for 'mutual support' in Model 1 indicates that coworkers scoring 1 point higher on the daily mutual support could be expected to report 0.08 more 'sustainable job performance' on the same day. Hypothesis 1 was therefore supported. Model 2 further showed that coworkers with higher 'sleep quality', 'job requirements', 'workload stress', and 'RBSE' were more likely to report higher 'sustainable job performance'. For example, holding all the other variables constant, coworkers with higher 'RBSE' reported 0.18 more 'sustainable job performance', compared with coworkers in lower 'RBSE'. 
Table 2. Hierarchical linear modeling with daily mutual support to predict sustainable job performance

\begin{tabular}{|c|c|c|c|}
\hline \multirow{2}{*}{ Variables } & \multicolumn{3}{|c|}{ DV: Sustainable Job Performance } \\
\hline & Model 1 & Model 2 & Model 3 \\
\hline \multicolumn{4}{|l|}{ Fixed effects: } \\
\hline Intercept & $3.65^{* *}(0.05)$ & $3.64 * *(0.05)$ & $3.64 * *(0.05)$ \\
\hline Sleep quality & $0.07^{* *}(0.02)$ & $0.05 *(0.02)$ & $0.05 *(0.02)$ \\
\hline Job requirements & $0.20 * *(0.03)$ & $0.17^{* *}(0.03)$ & $0.16^{* *}(0.03)$ \\
\hline Workload stress & $0.29 * *(0.02)$ & $0.28^{* *}(0.02)$ & $0.28 * *(0.02)$ \\
\hline Mutual support & $0.08^{* *}(0.03)$ & $0.05^{\dagger}(0.03)$ & $0.05^{\dagger}(0.03)$ \\
\hline Role breadth self-efficacy & & $0.18 * *(0.03)$ & $0.18^{* *}(0.03)$ \\
\hline $\begin{array}{l}\text { Mutual support* Role } \\
\text { breadth self-efficacy }\end{array}$ & & & $0.05 *(0.03)$ \\
\hline \multicolumn{4}{|l|}{ Random effects: } \\
\hline Between-person & 0.49 & 0.44 & 0.44 \\
\hline Within-person & 0.44 & 0.43 & 0.43 \\
\hline
\end{tabular}

\subsection{Moderating Effect Hypothesis}

Hypothesis 2 concerns the moderation role of 'RBSE' and demonstrates that among coworkers who are high on 'RBSE', those with higher daily 'mutual support' achieve higher level of 'sustainable job performance'. Conversely, among coworkers low on 'RBSE', those with lower daily 'mutual support' achieve lower level of 'sustainable job performance'. As shown in Model 3, the data supported Hypothesis 2 in that the interactive effect of 'mutual support' and 'RBSE' was positively significant when predicting 'sustainable job performance'. The predictor 'mutual support' and moderator 'RBSE' are both significant with the interaction term added, where partial moderation has occurred. Figure 2 depicts this moderation effect graphically, showing that coworkers with high 'mutual support' experience a strong, positive relationship between daily 'mutual support' and 'sustainable job performance', whereas the relationship was weak for those with low 'RBSE'.

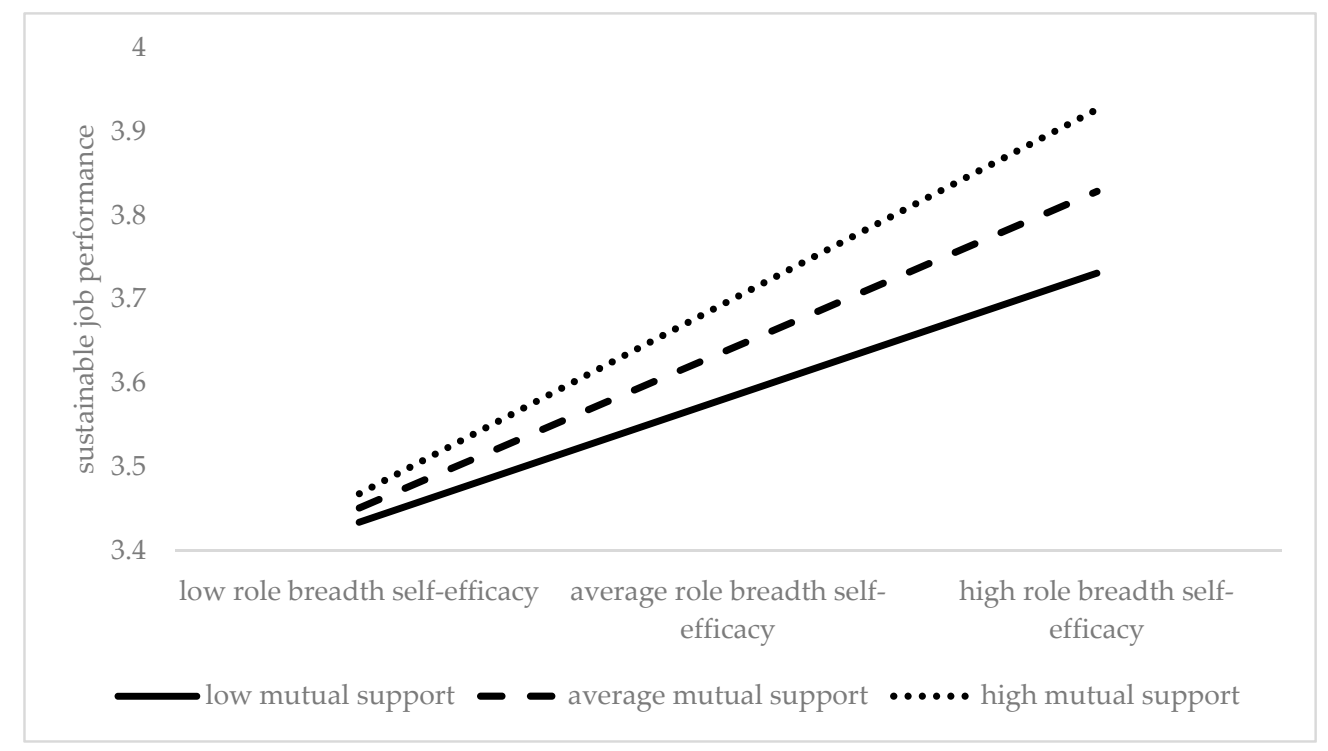

Figure 2. Moderation effect of role breadth self-efficacy. 
Notably, the between-person variation reflects the variation in coefficients across individuals, the within-person variation demonstrates the fluctuation of job performance over ten days within individual. A relatively larger value of this between or within-person variation indicates that the relationship between the predictor and 'sustainable job performance' differs on inter- and intra-individual level. As the random effects have shown, the variation from individual differences is slightly larger than the time variation within individual, both of which provide the source of random variation in 'sustainable job performance'.

Low mutual support and low RBSE represent participants scored one standard deviation below the grand mean on the respective measures. High mutual support and high RBSE represent participants scored one standard deviation above the grand mean.

\section{Discussion and Concluding Remarks}

The purpose of this study is to investigate how a worker's daily job performance in a young firm operating in coworking space varies within oneself (within-person sustainability), and compare it with that between workers (between-person sustainability). In the recent decade, coworking space has flourished as it has been regarded by the governments of innovation-driven economies as an important aspect of the city's startup ecosystem to encourage entrepreneurship. As a result, more new firms are formed and house their knowledge workers in these spaces on a periodic lease or on-demand, rather than the traditional office space on a fixed-term lease [70,71]. Despite the growing interest in the sustainability of young firms among the policymakers and research scholars, the extant literature has still left the dynamic predictors of young firms' sustainability almost unexplored. Few studies have attempted multilevel studies of employees' sustainable job performance in young firms characterized by working alongside other firms in a coworking space.

Our study supported all the hypotheses. Daily mutual support that a worker receives in a young firm operating in a coworking space was found to be positively related to the worker's daily sustainable job performance after controlling for daily sleep quality, daily job requirements and daily workload stress, validating Hypothesis 1. A worker's daily RBSE was empirically established as a significant positive moderator in the link between the daily mutual support the worker receives and the worker's daily sustainable job performance, confirming Hypothesis 2.

\subsection{Theoretical Implications}

With ten waves of data from 101 members working at young firms in coworking spaces (1010 observations over a period of ten days), our study offers several contributions to the literature that has limited multilevel studies on young firms' sustainability. Specifically, we put forward current thinking about the sustainability of workers' daily job performance by testing the significance of daily mutual support as an essential predictor, as well as the potential moderating role of daily RBSE in the relationship between daily mutual support and workers' daily sustainable job performance. In addition, we made comparison between within-person and between-person differences in daily job performance.

While past research has focused on the direct relationship among social interaction, organizational support and job performance [72,73], we have drawn attention to one crucial dimension of social interaction in the context of young firms, that is, coworkers' mutual support by examining the extent to which daily mutual support influences workers' sustainable job performance. As coworkers' mutual support showed a positive effect on workers' sustainable job performance, this finding suggests a supportive environment can have a beneficial effect on workers' sustainable job performance such that on a day that workers perceive higher coworker support, they would report higher job performance for that day.

Second, based on the established relationship between daily mutual support and daily sustainable job performance, we further tested the moderating role of daily RBSE within this relationship. Vancouver et al. did not find any significant relationship between RBSE and job performance due 
to the existence of overconfidence [74]. We expand this process theoretically by analyzing daily job performance in the context of young firms. The result that daily RBSE is a significant moderator for the effect of daily mutual support on daily job performance can be explained by the fact that participants' self-reported ratings on their performance were measured every evening over ten days, enabling participants to estimate how they carry out their daily tasks. Their awareness that their performance would also be evaluated by their peers might lead them to reduce overconfidence and avoid underperformance.

Last but not least, a diary design and a novel multilevel longitudinal analysis help us find that the state fluctuations within individual accounts for almost half the variation in job performance, the rest of which are explained by the differences across individuals. Apart from the importance of traits on job performance, significant variability in within-individual level suggests daily mutual support and RBSE may increase the workers' sustainable job performance as well as the sustainability of young firms. The level of invisible external support and RBSE fluctuate on a daily basis [75,76]. Sustainable job performance has also been found to be highly fluctuating, with 44.57 per cent of variation explained at the within-individual level [77]. In line with previous diary studies, we extend the research on job performance into a coworking space context, aiming to provide new perspectives and suggestions on sustainable job performance for young firms.

\subsection{Managerial Implications}

Our results have several important implications for the managers of both coworking space operators and tenant firms. First, employees are the backbone of any organization. It is their continuous effort and sustainable job performance that contribute to company performance and thus drive business success. Based on a study of digital economy companies, Jabłoński observed that managers can be inspired to consider sustainability-related factors in their projects [78]. Managers in young firms should find ways to enhance workers' sustainable job performance by helping workers realize how their work contributes towards company's sustainability goals and find meaning in their work. Once workers understand the meaning of their contributions, they are likely to work with more passion and excitement, and therefore be more productive. This will in turn enable the young firm to sustain a high level of performance.

Second, as higher daily mutual support is found to be associated positively with a higher level of job performance, managers of coworking spaces should build a friendly and cooperative environment rather than a competitive one. To ensure everyone's ideas are respected and discussions among coworkers are constructive and beneficial, ground rules that promote collaboration and eliminate rude behavior should be emphasized at the workplace. Disrespectful behavior not only hinders coworkers from performing actively, but also can be contagious, causing problems ranging from increased stress to lost productivity. Such behavior should be stamped out by putting in place processes for incident reporting and management. Coworking space managers should be trained and empowered to deal with disrespectful behavior by providing clear and constructive feedback and coaching to the offending coworkers. In more severe situations, disciplinary actions might be required. In such ways, a psychologically safe and collaborative environment can be established.

Third, the positive relationship between mutual support and sustainable job performance will be enhanced with a high level of RBSE. This result suggests that managers can implement practices to foster workers' RBSE, thereby developing their abilities and sustaining their job performance. RBSE can be enhanced via organizational intervention such as increased task control, training and membership of an active improvement group [79]. In young firms, most workers are required to multi-task to optimize limited resources. So, inherently, RBSE is important in young firms, and our findings strengthen this argument. To help expand workers' task control and raise RBSE, managers in young firms can consider granting workers who are high in skills but low in RBSE greater autonomy. Managers can organize training involving horizontal skills such as conflict resolution (to do the job) or vertical skills such as preventative maintenance (to gain technical mastery). Equipped with a range of skills, workers 
will feel more confident when facing challenging tasks. By encouraging workers to join professional development groups in the form of monetary support (e.g., reimbursement of membership fees) or non-monetary support (e.g., time off), managers in young firms can bolster their workers' RBSE.

\subsection{Policy Implications}

Our findings have important implications for policy makers. First, in innovation-driven economies, entrepreneurship has gained increasing attention as a key driver for socio-economic growth. To encourage formation of new ventures, local governments can formulate policies to set aside land and buildings for development of infrastructure such as coworking space. To foster the growth of young firms, public policymakers can introduce programs to develop the coworking spaces into key nodes of a larger innovation and startup ecosystem in the city [70]. Joining the membership of coworking space will enable young firms to gain access to government-sponsored venture-friendly support programs. Second, to provide greater level of support for entrepreneurs, coaching programs can be introduced to render the required assistance for problem solving. For example, an online coaching program between established and young entrepreneurs in the north of England was found to furnish the required quality and quantity of support in all functional aspects [80].

\subsection{Limitations and Future Research}

The current study entails several limitations. First, although the peer responses of participants' job performance converged with self-reports, other factors besides objective performance may have influenced the peer ratings. For example, participants were inclined to nominate peers who got along well with them to rate on their job performance. It is therefore possible that participants shared the highlights or lowlights of their workdays with their peers during break time or lunch time, thereby influencing the peers to make inferences about the participants' overall job performance. Future research on job performance may include a measure assessing the extent to which individuals discuss their workdays with their coworkers.

Second, although there are various dimensions in job performance, our study focuses on task performance such as the quantity and quality of work output. Katz and Kahn first divided job performance into task performance and contextual performance, which is also known as relational performance [81]. The former refers to the effectiveness of activities contributing to business development. The latter reflects the effectiveness of social environment and cultural context that serve as catalysts for task activities and process, which is also an important element of job performance. Future studies could explore how mutual support relates to other dimensions in job performance (e.g., contextual performance) and other outcomes important to young firms, which would help us to better understand their sustainability.

Author Contributions: Conceptualization, S.C. and Y.-P.H.; Methodology, S.C.; Software, S.C.; Validation, S.C. and S.L.; Formal Analysis, S.C., S.L., and Y.P.-H.; Investigation, S.C., S.L., and Y.P.-H.; Resources, S.C.; Data Curation, S.C. and S.L.; Writing-Original Draft Preparation, S.L., and S.C.; Writing-Review \& Editing, S.C. and Y.P.H.; Visualization, S.C. and S.L.; Supervision, S.C.; Project Administration, S.C.; Funding Acquisition, S.C.

Funding: This research was funded by $\mathrm{Ng}$ Teng Fong Charitable Foundation (NTFCF) Research Funding, grant number R-317-000-133-720. The APC was funded by NTFCF Research Funding, grant number R-317-000-133-720.

Conflicts of Interest: The authors declare no conflict of interest. The funders had no role in the design of the study; in the collection, analyses, or interpretation of data; in the writing of the manuscript, or in the decision to publish the results.

\section{References}

1. Campbell, J.P.; Wiernik, B.M. The modeling and assessment of work performance. Annu. Rev. Organ. Psychol. Organ. Behav. 2015, 2, 47-74. [CrossRef]

2. Kim, Y.; Ployhart, R.E. The effects of staffing and training on firm productivity and profit growth before, during, and after the Great Recession. J. Appl. Psychol. 2014, 99, 361. [CrossRef] [PubMed] 
3. Barrick, M.R.; Stewart, G.L.; Piotrowski, M. Personality and job performance: Test of the mediating effects of motivation among sales representatives. J. Appl. Psychol. 2002, 87, 43. [CrossRef] [PubMed]

4. He, H.; Wang, W.; Zhu, W.; Harris, L. Service workers' job performance: The roles of personality traits, organizational identification, and customer orientation. Eur. J. Mark. 2015, 49, 1751-1776. [CrossRef]

5. Masa'deh, R.; Shannak, R.; Maqableh, M.; Tarhini, A. The impact of knowledge management on job performance in higher education: The case of the University of Jordan. J. Enterp. Inf. Manag. 2017, 30, 244-262. [CrossRef]

6. Cano, C.R.; Carrillat, F.A.; Jaramillo, F. A meta-analysis of the relationship between market orientation and business performance: Evidence from five continents. Int. J. Res. Market 2004, 21, 179-200. [CrossRef]

7. Barrick, M.R.; Mount, M.K. The big five personality dimensions and job performance: A meta-analysis. Pers. Psychol. 1991, 44, 1-26. [CrossRef]

8. Judge, T.A.; Thoresen, C.J.; Bono, J.E.; Patton, G.K. The job satisfaction-job performance relationship: A qualitative and quantitative review. Psychol. Bull. 2001, 127, 376-407. [CrossRef]

9. Judge, T.A.; Bono, J.E. Relationship of Core Self-Evaluations Traits-Self-Esteem, Generalized Self-Efficacy, Locus of Control, and Emotional Stability-With Job Satisfaction and Job Performance: A Meta-Analysis. J. Appl. Psychol. 2001, 86, 80-92. [CrossRef]

10. Callewaert, J.; Marans, R.W. Measuring progress over time: The sustainability cultural indicators program at the University of Michigan. In Handbook of Theory and Practice of Sustainable Development in Higher Education; Springer: Cham, Switzerland, 2017; pp. 173-187.

11. Jiang, W.; Zhao, X.; Ni, J. The Impact of Transformational Leadership on Employee Sustainable Performance: The Mediating Role of Organizational Citizenship Behavior. Sustainability 2017, 9, 1567. [CrossRef]

12. Bakker, A.B.; Demerouti, E. Job Demands-Resources theory. In Wellbeing: A Complete Reference Guide; Cooper, C., Chen, P., Eds.; Wiley-Blackwell: Chichester, UK, 2014.

13. Bakker, A.B.; Demerouti, E. Job Demands-Resources theory: Taking stock and looking forward. J. Occup. Health Psychol. 2017, 22, 273-285. [CrossRef] [PubMed]

14. Bakker, A.B.; Demerouti, E. Multiple levels in job demands-resources theory: Implications for employee well-being and performance. In Handbook of Wellbeing; Diener, E., Oishi, S., Tay, L., Eds.; DEF Publishers: Salt Lake City, UT, USA, 2018.

15. Sedláček, P.; Sterk, V. The growth potential of startups over the business cycle. Am. Econ. Rev. 2017, 107, 3182-3210. [CrossRef]

16. Lechler, T. Social Interaction: A Determinant of Entrepreneurial Team Venture Success. Small Bus. Econ. 2001, 16, 263-278. [CrossRef]

17. Pinto, M.B.; Pinto, J.K. Project team communication and cross-functional cooperation in new program development. J. Prod. Innov. Manag. 1990, 7, 200-212. [CrossRef]

18. Mullen, B.; Copper, C. The relation between group cohesiveness and performance: An integration. Psychol. Bull. 1994, 115, 210. [CrossRef]

19. Levine, J.M.; Moreland, R.L. Progress in small group research. Ann. Rev. Psychol. 1990, 41, 585-634. [CrossRef]

20. Gemünden, H.G.; Högl, M. Teamarbeit in innovativen Projekten: Eine kritische Bestandsaufnahme der empirischen Forschung. Ger. J. Hum. Resour. Manag. 1998, 12, 277-301. [CrossRef]

21. Tjosvold, D.; Tjosvold, M.M. Cooperation theory, constructive controversy, and effectiveness: Learning from crises. In Team Effectiveness and Decision Making in Organizations; Jossey-Bass: San Francisco, CA, USA, 1995; pp. 79-112.

22. Sroka, W.; Jabłoński, A.; Jabłoński, M. Cooperative business models in steel enterprises in Poland. Metalurgija 2013, 52, 565-568.

23. Davidson, L.; Chinman, M.; Kloos, B.; Weingarten, R.; Stayner, D.; Tebes, J.K. Peer support among individuals with severe mental illness: A review of the evidence. Clin. Psychol. Sci. Pract. 1999, 6, 165-187. [CrossRef]

24. Marcelissen, F.H.G.; Winnubst, J.A.M.; Buunk, B.; de Wolff, C.J. Social support and occupational stress: A causal analysis. Soc. Sci. Med. 1988, 26, 365-373. [CrossRef]

25. Baruch-Feldman, C.; Brondolo, E.; Ben-Dayan, D.; Schwartz, J. Sources of social support and burnout, job satisfaction, and productivity. J. Occup. Health Psychol. 2002, 7, 84. [CrossRef] [PubMed]

26. Murphy, K.R. Job performance and productivity. Psychol. Organ. Integr. Sci. Pract. 1990, 157, 176. 
27. Genero, N.P.; Miller, J.B.; Surrey, J.; Baldwin, L.M. Measuring Perceived Mutuality in Close Relationships: Validation of the Mutual Psychological Development Questionnaire. J. Fam. Psychol. 1992, 6, 36-48. [CrossRef]

28. Murray, S.L.; Holmes, J.G. The Architecture of Interdependent Minds: A Motivation-Management Theory of Mutual Responsiveness. Psychol. Rev. 2009, 116, 908-928. [CrossRef] [PubMed]

29. Clarke, N.; Mahadi, N. Mutual recognition respect between leaders and followers: Its relationship to follower job performance and well-being. J. Bus. Eth. 2017, 141, 163-178. [CrossRef]

30. Coyne, J.C.; Bolger, N. Doing without social support as an explanatory concept. J. Soc. Clin. Psychol. 1990, 9 , 148-158. [CrossRef]

31. Deci, E.L.; Ryan, R.M. SpringerLink (Online service). In Intrinsic Motivation and Self-Determination in Human Behavior; Plenum: New York, NY, USA, 1985.

32. Andersen, S.M.; Chen, S.; Carter, C. Fundamental Human Needs: Making Social Cognition Relevant. Psychol. Inq. 2000, 11, 269-275.

33. Ilardi, B.C.; Leone, D.; Kasser, T.; Ryan, R.M. Employee and supervisor ratings of motivation: Main effects and discrepancies associated with job satisfaction and adjustment in a factory setting. J. Appl. Soc. Psychol. 1993, 23, 1789-1805. [CrossRef]

34. Brickson, S. The impact of identity orientation on individual and organizational outcomes in demographically diverse settings. Acad. Manag. Rev. 2000, 25, 82-101. [CrossRef]

35. Blau, P. Exchange and Power in Social Life; Routledge: Abingdon, UK, 2017.

36. Nguyen, T. STEAM-ME: A Novel Model for Successful Kaizen Implementation and Sustainable Performance of SMEs in Vietnam. Complexity 2019, 2019, 6048195. [CrossRef]

37. Bandura, A.; Walters, R.H. Social Learning Theory; Prentice-Hall: Englewood Cliffs, NJ, USA, March 1977.

38. Stajkovic, A.D.; Luthans, F. Social cognitive theory and self-efficacy: Goin beyond traditional motivational and behavioral approaches. Organ. Dyn. 1998, 26, 62-74. [CrossRef]

39. Anderson, E.S.; Wojcik, J.R.; Winett, R.A.; Williams, D.M. Social-cognitive determinants of physical activity: The influence of social support, self-efficacy, outcome expectations, and self-regulation among participants in a church-based health promotion study. Health Psychol. 2006, 25, 510. [CrossRef] [PubMed]

40. Yeo, G.B.; Neal, A. An examination of the dynamic relationship between self-efficacy and performance across levels of analysis and levels of specificity. J. Appl. Psychol. 2006, 91, 1088. [CrossRef] [PubMed]

41. Parker, S.K. Enhancing Role Breadth Self-Efficacy: The Roles of Job Enrichment and Other Organizational Interventions. J. Appl. Psychol. 1998, 83, 835-852. [CrossRef] [PubMed]

42. Parker, S.K.; Williams, H.M.; Turner, N. Modeling the antecedents of proactive behavior at work. J. Appl. Psychol. 2006, 91, 636. [CrossRef]

43. Griffin, M.A.; Parker, S.K.; Mason, C.M. Leader vision and the development of adaptive and proactive performance: A longitudinal study. J. Appl. Psychol. 2010, 95, 174. [CrossRef] [PubMed]

44. Vroom, V.H. Work and Motivation; Wiley: New York, NY, USA, 1964.

45. Fuller, J.B., Jr.; Marler, L.E.; Hester, K. Bridge building within the province of proactivity. J. Organ. Behav. 2012, 33, 1053-1070. [CrossRef]

46. Grant, A.M.; Ashford, S.J. The dynamics of proactivity at work. Res. Organ. Behave. 2008, 28, 3-34. [CrossRef]

47. Zapata-Phelan, C.P.; Colquitt, J.A.; Scott, B.A.; Livingston, B. Procedural justice, interactional justice, and task performance: The mediating role of intrinsic motivation. Organ. Behav. Hum. Decis. Process. 2009, 108, 93-105. [CrossRef]

48. Vancouver, J.B.; Kendall, L.N. When self-efficacy negatively relates to motivation and performance in a learning context. J. Appl. Psychol. 2006, 91, 1146. [CrossRef]

49. Cervone, D.; Wood, R. Goals, feedback, and the differential influence of self-regulatory processes on cognitively complex performance. Cogn. Ther. Res. 1995, 19, 519-545. [CrossRef]

50. Tims, M.B.; Bakker, A.; Derks, D. Daily job crafting and the self-efficacy-performance relationship. J. Manag. Psychol. 2014, 29, 490-507. [CrossRef]

51. DeGuzman, G.V.; Tang, A.I. Working in the Unoffice: A Guide to Coworking for Indie Workers, Small Businesses, and Nonprofits; Night Owls Press LLC: San Francisco, CA, USA, 2011.

52. Carpinello, S.E.; Knight, E.L.; Janis, L. A qualitative study of the perceptions of the meaning of self-help, self-help group processes and outcomes by self-help group leaders, members, and significant others. 1991; Unpublished manuscript. 
53. McAdam, M.; Marlow, S. Building futures or stealing secrets? Entrepreneurial cooperation and conflict within business incubators. Int. Small Bus. J. 2007, 25, 361-382. [CrossRef]

54. Podsakoff, P.M. Organ DW. Self-reports in organizational research: Problems and prospects. J. Manag. 1986, 12, 531-544.

55. Meyer, J.P.; Allen, N.J. Commitment in the Workplace: Theory, Research, and Application; Sage: Newcastle upon Tyne, UK, 27 January 1997.

56. Goffin, R.D.; Gellatly, I.R. A multi-rater assessment of organizational commitment: Are self-report measures biased? J. Organ. Behav. Int. J. Ind. Occup. Organ. Psychol. Behav. 2001, 22, 437-451. [CrossRef]

57. Welbourne, T.M.; Johnson, D.E.; Erez, A. The role-based performance scale: Validity analysis of a theory-based measure. Acad. Manag. J. 1998, 41, 540-555.

58. Nebes, R.D.; Buysse, D.J.; Halligan, E.M.; Houck, P.R.; Monk, T.H. Self-Reported Sleep Quality Predicts Poor Cognitive Performance in Healthy Older Adults. J. Gerontol. Ser. B 2009, 64B, 180-187. [CrossRef]

59. Yuan, F.; Woodman, R.W. Innovation behaviour in the workplace: The role of performance and image outcome expectations. Acad. Manag. J. 2010, 53, 323-342. [CrossRef]

60. Cavanaugh, M.A.; Boswell, W.R.; Roehling, M.V.; Boudreau, J.W. An Empirical Examination of Self-Reported Work Stress Among U.S. Managers. J. Appl. Psychol. 2000, 85, 65-74. [CrossRef]

61. Azar, B. Poor recall mars research and treatment: Inaccurate self-reports can lead to faulty research conclusions and inappropriate treatment. APA Monitor 1997, 28.

62. Schwarz, N. Self-reports: How the questions shape the answers. Am. Psychol. 1999, 54, 93. [CrossRef]

63. Hox, J.J. Multilevel Analysis: Techniques and Applications, 2nd ed.; Routledge: New York, NY, USA, 2010.

64. Wooldridge, J.M. Fixed-Effects and Related Estimators for Correlated Random-Coefficient and Treatment-Effect Panel Data Models. Rev. Econ. Stat. 2005, 87, 385-390. [CrossRef]

65. Ilies, R.; Scott, B.A.; Judge, T.A. The Interactive Effects of Personal Traits and Experienced States on Intraindividual Patterns of Citizenship Behavior. Acad. Manag. J. 2006, 49, 561-575. [CrossRef]

66. Sonnentag, S. Recovery, Work Engagement, and Proactive Behavior: A New Look at the Interface Between Nonwork and Work. J. Appl. Psychol. 2003, 88, 518-528. [CrossRef] [PubMed]

67. Finch, W.H. Multilevel Modeling Using R; Taylor \& Francis Group/CRC Press: Boca Raton, FL, USA, 2014.

68. Chatterjee, S.; Hadi, A.S. Regression Analysis by Example; John Wiley \& Sons: Hoboken, NJ, USA, 2015.

69. Berman, S.L.; Montgomery, M.J.; Kurtines, W.M. The development and validation of a measure of identity distress. Id. Int. J. Theory Res. 2004, 4, 1-8. [CrossRef]

70. Cheah, S.; Ho, Y.P. Coworking and Sustainable Business Model Innovation in Young Firms. Sustainability 2019, 11, 2959. [CrossRef]

71. Cheah, S.; Ho, Y.P.; Lim, P. Role of Public Science in Fostering the Innovation and Startup Ecosystem in Singapore. Asia Res. Policy 2016, 7, 78-93.

72. Hochwarter, W.A.; Witt, L.A.; Treadway, D.C.; Ferris, G.R. The Interaction of Social Skill and Organizational Support on Job Performance. J. Appl. Psychol. 2006, 91, 482-489. [CrossRef]

73. Sandoval, L.R.; González, B.L.; Stone, W.S.; Guimond, S.; Rivas, C.T.; Sheynberg, D.; Kuo, S.S.; Eack, S.; Keshavan, M.S. Effects of peer social interaction on performance during computerized cognitive remediation therapy in patients with early course schizophrenia: A pilot study. Schizophr. Res. 2019, 203, 17-23. [CrossRef]

74. Vancouver, J.B.; Thompson, C.M.; Tischner, E.C.; Putka, D.J. Two studies examining the negative effect of self-efficacy on performance. J. Appl. Psychol. 2002, 87, 506. [CrossRef]

75. Bolger, N.; Zuckerman, A.; Kessler, R.C. Invisible support and adjustment to stress. J. Pers. Soc. Psychol. 2000, 79, 953. [CrossRef] [PubMed]

76. Tims, M.; Bakker, A.B.; Derks, D. Development and validation of the job crafting scale. J. Vocat. Behav. 2012, 80, 173-186. [CrossRef]

77. Xanthopoulou, D.; Baker, A.B.; Heuven, E.; Demerouti, E.; Schaufeli, W.B. Working in the sky: A diary study on work engagement among flight attendants. J. Occup. Health Psychol. 2008, 13, 345. [CrossRef] [PubMed]

78. Jabłoński, M. Value Migration to the Sustainable Business Models of Digital Economy Companies on the Capital Market. Sustainability 2018, 10, 3113. [CrossRef]

79. Axtell, C.M.; Parker, S.K. Promoting role breadth self-efficacy through involvement, work redesign and training. Hum. Relat. 2003, 56, 113-131. [CrossRef] 
80. Fielden, S.L.; Hunt, C.M. Online coaching: An alternative source of social support for female entrepreneurs during venture creation. Int. Small Bus. J. 2011, 29, 345-359. [CrossRef]

81. Katz, D.; Kahn, R.L. The social psychology of organizations. Adm. Sci. Q. 1978, 46, 118.

(C) 2019 by the authors. Licensee MDPI, Basel, Switzerland. This article is an open access article distributed under the terms and conditions of the Creative Commons Attribution (CC BY) license (http://creativecommons.org/licenses/by/4.0/). 